\title{
Corneal confocal microscopy in a healthy Brazilian sample
}

\author{
Microscopia confocal em córneas de brasileiros saudáveis \\ Gabriela Dieckmann 1,2, Camila Pupe ${ }^{1,2}$, Osvaldo J. M. Nascimento ${ }^{1,2}$
}

\begin{abstract}
Objective: This study aims to evaluate the characteristics of the corneal sub-basal plexus by performing in vivo confocal microscopy of healthy Brazilians to provide reference values for the Brazilian population. Method: This study is an observational, cross-sectional, descriptive study comparing corneas from 55 healthy Brazilian individuals across the age span of 20-70 years. Results: The average number of fibers was $5.35 \pm 1.36$, fiber density was $33.4 \pm 8.5$ fibers per field, and the mean number of Langerhans cells was $5.13 \pm 8.10$. A correlation between the average number of fibers and age showed an inverse relationship between the number and density of fibers and age for women $(p<0.05)$. In the multivariate analysis, each annual increase of age showed an average increase of $1.017(95 \% \mathrm{Cl}: 1.008$ to 1.026$)$ in the number of Langerhans cells, adjusting for sex and thickness. Conclusion: Compared to other samples, this Brazilian population showed a higher average number of fibers, though further studies with a larger sample should be performed.
\end{abstract}

Keywords: cornea, confocal microscopy, Langerhans cells, fibers, age.

\section{RESUMO}

Objetivo: Este estudo tem como objetivo avaliar as características morfológicas do plexo sub-basal da córnea por microscopia confocal in vivo com indivíduos brasileiros saudáveis para fornecer uma referência para a população brasileira. Método: Este trabalho é um estudo observacional, descritivo, transversal comparativo com microscopia confocal de córnea a partir de 55 indivíduos brasileiros saudáveis na faixa etária de $70 \pm 20$ anos de idade. Resultados: Número médio de fibras foi $5,35 \pm 1,36$, a densidade foi de 33,4 \pm 8,5 fibras por campo e de células de Langerhans foi 5,13 \pm 8,10. Uma correlação entre o número médio de fibras e da idade dos indivíduos mostrou uma relação inversa entre o número e densidade de fibras, e idade para as mulheres, ( $p<0,05)$. Na análise multivariada, cada aumento anual de idade apresentou um aumento médio de 1,017 (IC95\%: 1,008-1,026) no número de células de Langerhans, ajustado para sexo e espessura. Conclusão: Em comparação com outras amostras, esta população brasileira apresentou um maior número médio de fibras embora estudos com número maior de amostras necessitem ser realizados.

Palavras-chave: córnea, microscopia confocal, células de Langerhans, fibras, idade.

Corneal innervation, especially in the sub-basal epithelial plexus, is an important factor in the reflex arc and is involved in corneal protection and corneal epithelium maintenance ${ }^{1,2}$. While the plexus sub-basal epithelial has been studied using electron and light microscopy, these studies are hampered by the fact that corneal nerve fibers degenerate within 14 hours after death ${ }^{1}$. The emergence of confocal microscopy adapted for in vivo use has allowed the study of all layers of the cornea, including its innervation and its relationship with Langerhans cells (LCs).

LCs are part of a main histocompatibility complex class II (MHCII) and work to transport tissue to capture, process, and present antigens ${ }^{3}$. As cells mature, they begin to have less capacity to capture antigens and then turn into a strong stimulator of $\mathrm{T}$ lymphocytes. In general, the density changes and number of LCs can help us understand the immune mechanisms of the cornea ${ }^{4}$ as they are closely related to the sub-basal epithelial plexus. They increase in number and density in inverse relation to the number and density of the fiber plexus in the presence of corneal infection (keratitis) ${ }^{5}$.

More recently, the assessment of LCs and unmyelinated fibers in the cornea has become the subject of study for other medical specialties, particularly neurology. Corneal confocal microscopy (CCM) is a noninvasive method for diagnosing and monitoring systemic diseases such as diabetic neuropathy ${ }^{6}$; fewer nerve bundles correlate with a loss of corneal sensitivity and neuropathy severity in type 1 diabetic patients. An early diagnosis of peripheral neuropathy is made by observing a reduction of sub-basal epithelial plexus fibers,

${ }^{1}$ Universidade Federal Fluminense, Programa de Pós-Graduação em Neurologia/Neurociências, Niteroi RJ, Brazil;

${ }^{2}$ Universidade Federal Fluminense, Hospital Universitário Antonio Pedro, Núcleo de Pesquisa Clínica em Neurologia e Neurociências - NeuroUPC, Niteroi RJ, Brazil. Correspondence: Osvaldo J. M. Nascimento; Rua Siqueira Campos, 53/1204; 22031-071 Rio de Janeiro RJ, Brasil; E-mail: osvaldo_nascimento@hotmail.com Conflict of interest: There is no conflict of interest to declare.

Received 01 March 2015; Received in final form 24 June 2015; Accepted 16 July 2015. 
which occurs even before a reduction in corneal sensitivity ${ }^{7}$ Improved blood glucose levels in type 1 diabetic patients undergoing pancreas transplantation was shown to recover a number of nerve fibers.

Fabry disease also evolves with peripheral neuropathy and has been studied with CCM. It is characterized by a reduction in the number and the density of nerve fibers in the plexus sub-epithelial basement ${ }^{8}$. CCCM has also been employed in diagnosing peripheral neuropathy in patients undergoing chemotherapy as some of these drugs can dose-dependently induce peripheral neuropathy ${ }^{9}$.

Reference levels are largely based on North American samples; it is unclear what Brazilian population values are. This study aims to evaluate the morphological characteristics of the sub-basal plexus with in vivo cornealCCM in healthy Brazilian individuals to provide reference values that may be used for comparison and future research.

\section{METHOD}

\section{Design and study population}

This was an observational, cross-sectional descriptive study conducted with a convenience sample of healthy individuals referred from the Hospital Universitário Antonio Pedro (HUAP), Universidade Federal Fluminense (UFF). We included all individuals who signed the informed consent form, between 21 and 70 years of age, and of both sexes. We excluded subjects who had a history of trauma or corneal diseases and/or peripheral nerve disorders, had previous eye surgery, had a history of contact lens use, had more than 6 months of exposure to a potentially toxic drug to nerves and/or the cornea, or had cognitive and/or sensory deficits that would prevent them from performing the exam.

\section{Data collection by in vivo CCM}

The confocal microscope used in the study was an HRT II coupled to the cornea module from Heidelberg Engineering, Germany. The objective lenses were prepared with one drop of Vidisic ${ }^{\circ}$ gel (Bausch Lomb), and another drop was instilled into the lower fornix of the patient's conjunctiva. Anestalcon ${ }^{\circ}$ (proparacaine $\mathrm{HCl} 0.5 \%$, Alcon) anesthetic drops were instilled into the patient's eye prior to initiation of the study.

The patient was positioned correctly and comfortably on the device and was oriented to fix their look for the examination. The control of the central perpendicular alignment of the cornea was obtained by observing the red reflex laser corneal shown on the handset screen. By identifying the well-focused epithelium in the corneal apex, images were captured at 0 microns depth for the first picture. The focus deepened, and sequential images were recorded to the level of the posterior stroma. Images were acquired in sequence and separated at a distance of approximately 1 micron and a fixed field of $0.16 \mathrm{~mm}^{2}$. The same procedure was performed on both eyes.
The examination in both eyes lasted about 10 minutes. After capturing the images in both eyes, the Tomocap was discarded, and another drop of gel was instilled in the eye. The individual was then released and received guidance to instill lubricating eye drops during the day of the exam (offered to the individual).

The images obtained during the examination were $384 \times 384$ pixels over an area of $400 \mu \mathrm{m}^{2}$ and were stored in the computer coupled to the confocal system. The 5 best pictures of the sub-basal plexus epithelial of each eye were selected for a total of 10 images per individual. The blinded images were separately evaluated by three observers: an ophthalmologist (G.D.) and two neurologists (C.P. and O.J.M.N.). The following parameters previously established were evaluated: number and fiber density (defined as \# of fibers $\times 0.16$ ), number and LC density, degree of tortuosity (no fibers, grade 1 for parallel and slightly crooked fibers; grade 2 for twisted, non-parallel fibers; and grade 3 for tortuous fibers without direction), and thickness (categorized as thick, medium, or thin fibers) (Figure 1).

\section{Statistical analysis}

All statistical procedures were performed using the computer programs Microsoft Excel ${ }^{\odot}$ and SPSS (Statistical Package for Social Science) version 16.0 and statistical programming language R. Analyses were performed according to the following steps:

a) Description of variables and study population: a descriptive analysis of the population was performed by calculating the percentage distribution of the categories when the variables were categorical and the mean and standard deviation (SD) when variables were continuous or discrete. The following categorical variables were included: sex, fiber tortuosity (parallel, not parallel, not parallel - same direction, not parallel - without direction), and thickness (none, fine, medium, large). All analyses were performed for the entire population and stratified by sex.

b) Intra and inter-rater reliability: Fifty-five healthy subjects were included. For each individual, 10 pictures were taken ( 5 of the each eye), totaling 550 individual photos, which were evaluated by 3 observers. For the degree of reliability of categorical variables, simple agreement was calculated (percentage of concordant numbers), as were Cohen's kappa coefficients and their respective 95\% confidence intervals (CIs) and weighted kappas. The criterion of Landis and $\mathrm{Koch}^{20}$ was used to interpret agreement. Inter-observer agreement was verified in accordance for the right eye, left eye, and all photos. For the degree of reliability of continuous or discrete variables, an evaluation of intra-observer variability through the intraclass correlation coefficient (ICC) with respective 95\%CIs, and inter-observer analysis was performed by comparison analysis means ( $\mathrm{t}$ test for normally distributed variables and Mann-Whitney U or Kruskal-Wallis H tests for those variables that did not follow normal assumptions), analysis of variance (ANOVA), and correlation of variables between observers 


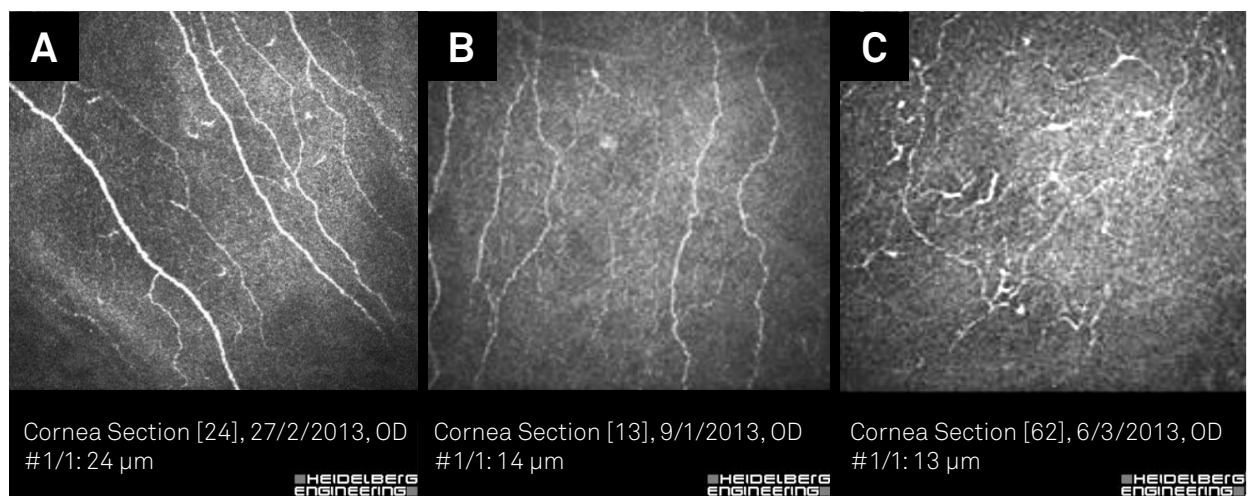

Figure 1. Confocal microscope images of corneas showing (A) thick, parallel fibers; (B) parallel fibers of medium thickness; and (C) thin non-parallel, unorganized fibers.

(Pearson correlation for variables with normal distributions and Spearman for those that were non-parametric).

c) Descriptive analysis of the variables: In this stage, due to the variables identified in CCM to be evaluated by the three observers, the measurements were aggregated with the purpose of obtaining a diagnosis for each individual (consensus among observers). So for the number of fibers and LCs, the measures were grouped using the "average" of observers 1 and 3, with observer 2 excluded due to low correlation with the others (see reliability analysis results). Categorical variables (tortuosity and thickness) were grouped using the measure of the "mode." As the concordance rate was not $100 \%$ between observers, all were included with the third observer's evaluation used in non-concordant cases. The variables of the study were explored and evaluated by age and sex. For continuous variables, mean comparisons were performed with the normality of those tested with the Kolmogorov-Smirnov and Shapiro tests. The difference of means was evaluated using the Mann-Whitney U or Kruskal-Wallis $\mathrm{H}$ tests for variables with normal and non-parametric distributions, respectively. The relationships between age variables and CCM parameters were calculated by Pearson correlation (normal distributions) and Spearman (nonparametric variables). In relation to qualitative variables (categorical variables), the percentage differences were evaluated using chi-square statistics. Fisher's exact test was considered when the expected frequencies were below $5 \%$. The influences of age and sex on CCM parameters were also investigated using simple linear regression and multiple (continuous and normally distributed variables) or generalized linear models (discrete or binary). Bivariate and multivariate analyzes were performed. The model fit was performed using ANOVA (nested models) and the Akaike information criterion (AIC, not nested models). In all analyses, $\mathrm{p}<0.05$ was considered significant.

\section{RESULTS}

Of the 55 healthy individuals evaluated, there were between 5-8 individuals per sex per age category. Within the age categories, there was no difference between the average age of the males or females (Figure 2). In general, the average age was $44.9 \pm 13.2$, number of fibers $5.35 \pm 1.36$, fiber density $33.4 \pm 8.5$ fibers per field, and LCs $5.13 \pm 8.10$ (Table 1 ). Considering the morphological fiber characteristics, $45 \%$ had parallel fibers (tortuosity), and $63.6 \%$ had average thickness. No statistically significant difference was observed between sexes for the assessed variables including age, age category, and CCM parameters.

\section{Inter- and intra-rater reliability}

Reliability between and within observers was calculated using Cohen's kappa, concordance correlation coefficient, and ICC. The results from the analysis of reliability revealed that observer 2 had low correlation with observers 1 and 3 and needed to be retrained on the scoring process. Data from all three observers is provided in the supplementary materials; however, due to the questionable validity of observer 2 , we have excluded them from the results presented below (see Table 2 and Figure 3).

Inter- and intra-rater reliability showed "substantial" agreement between observers 1 and 3 for tortuosity $(\mathrm{kappa}=0.75,95 \% \mathrm{CI} 0.70-0.80)$ and thickness (kappa $=0.80$, 95\%CI 0.76-0.85). Observations for the right and left eyes were similar to the total measurements.

No difference of sex within age groups

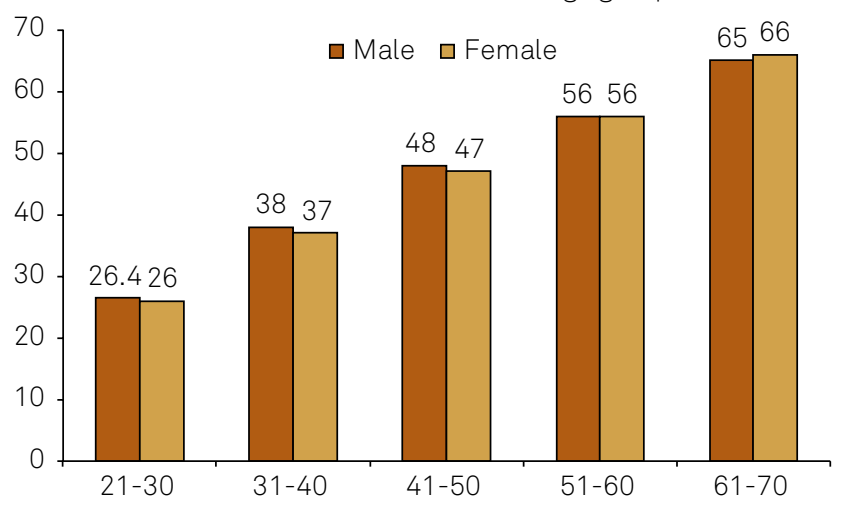

Figure 2. Average age within each age category by sex. 
Table 1. Population characteristics - Corneal confocal microscopy.

\begin{tabular}{|c|c|c|c|c|}
\hline \multirow{2}{*}{ Age } & Male $(n=25)$ & Female $(n=30)$ & Total $(n=55)$ & $p$-value \\
\hline & $46.2 \pm 13.5$ & $43.9 \pm 13.1$ & $44.9 \pm 13.2$ & 0.54 \\
\hline \multicolumn{5}{|l|}{ Age Category } \\
\hline 21-30 years & $5(20 \%)$ & $6(20 \%)$ & $11(20 \%)$ & \\
\hline $31-40$ years & $5(20 \%)$ & $6(20 \%)$ & $11(20 \%)$ & \\
\hline 41-50 years & $5(20 \%)$ & $8(27 \%)$ & $13(24 \%)$ & \\
\hline $51-60$ years & $5(20 \%)$ & $5(16.5 \%)$ & $10(18 \%)$ & \\
\hline $61-70$ years & $5(20 \%)$ & $5(16.5 \%)$ & $10(18 \%)$ & \\
\hline Total & $25(100 \%)$ & $30(100 \%)$ & $55(100 \%)$ & \\
\hline \multicolumn{5}{|l|}{$\mathrm{CCM}^{1}$} \\
\hline \# of fibers & $5.52 \pm 1.2$ & $4.20 \pm 1.5$ & $5.35 \pm 1.4$ & 0.37 \\
\hline Density of fibers & $34.5 \pm 7.6$ & $7.68 \pm 8.6$ & $33.4 \pm 8.5$ & 0.37 \\
\hline Langerhans cells & $7.00 \pm 10.9$ & $3.57 \pm 4.2$ & $5.13 \pm 8.1$ & 0.49 \\
\hline \multicolumn{5}{|l|}{ Width } \\
\hline Absence & $0(0 \%)$ & $2(6.7 \%)$ & $2(3.6 \%)$ & \\
\hline Thin & $6(24 \%)$ & $10(33.3 \%)$ & $16(29.1 \%)$ & \\
\hline Medium & $18(72 \%)$ & $17(56.7 \%)$ & $35(63.6 \%)$ & \\
\hline Large & $1(4 \%)$ & $1(3.3 \%)$ & $2(3.6 \%)$ & \\
\hline Total & $25(100 \%)$ & $30(100 \%)$ & $55(100 \%)$ & \\
\hline \multicolumn{5}{|l|}{ Tortuosity } \\
\hline Absence & $0(0 \%)$ & $2(6.7 \%)$ & $2(3.6 \%)$ & \\
\hline Parallel & $11(44 \%)$ & $14(46.7 \%)$ & $25(45.5 \%)$ & \\
\hline Non-parallel - same direction & $13(52 \%)$ & $12(40 \%)$ & $25(45.5 \%)$ & \\
\hline Non-parallel - no direction & $1(4 \%)$ & $2.6(7 \%)$ & $3(5.5 \%)$ & \\
\hline Total & $25(100 \%)$ & $30(100 \%)$ & $55(100 \%)$ & \\
\hline
\end{tabular}

Table 2. Data from all three observers.

\begin{tabular}{|c|c|c|c|c|c|c|c|c|c|c|c|c|c|c|c|c|c|c|}
\hline & \multicolumn{6}{|c|}{ Observer 1} & \multicolumn{6}{|c|}{ Observer 2} & \multicolumn{6}{|c|}{ Observer 3} \\
\hline & \multicolumn{2}{|c|}{ Right eye } & \multicolumn{2}{|c|}{ Left eye } & \multicolumn{2}{|c|}{ Total } & \multicolumn{2}{|c|}{ Right eye } & \multicolumn{2}{|c|}{ Left eye } & \multicolumn{2}{|c|}{ Total } & \multicolumn{2}{|c|}{ Right eye } & \multicolumn{2}{|c|}{ Left eye } & \multicolumn{2}{|c|}{ Total } \\
\hline & $\mathrm{N}$ & $\%$ & $\mathrm{~N}$ & $\%$ & $N$ & $\%$ & $\mathrm{~N}$ & $\%$ & $\mathrm{~N}$ & $\%$ & $\mathrm{~N}$ & $\%$ & $\mathrm{~N}$ & $\%$ & $\mathrm{~N}$ & $\%$ & $\mathrm{~N}$ & $\%$ \\
\hline \multicolumn{19}{|l|}{ Tortuosity* } \\
\hline Absence & 4 & 2 & 8 & 3 & 12 & 2 & 5 & 2 & 29 & 10 & 34 & 6 & 0 & 0 & 6 & 2 & 6 & 1 \\
\hline Parallel & 140 & 54 & 128 & 44 & 268 & 49 & 73 & 28 & 101 & 35 & 174 & 32 & 72 & 28 & 107 & 37 & 179 & 32 \\
\hline $\begin{array}{l}\text { Not parallel, but in } \\
\text { the same direction }\end{array}$ & 104 & 40 & 123 & 42 & 227 & 41 & 132 & 51 & 108 & 37 & 240 & 44 & 157 & 60 & 155 & 53 & 312 & 57 \\
\hline Same direction & 12 & 45 & 31 & 11 & 43 & 8 & 50 & 19 & 52 & 18 & 102 & 18 & 31 & 12 & 22 & 8 & 53 & 10 \\
\hline Total & 260 & 100 & 290 & 100 & 550 & 100 & 260 & 100 & 290 & 100 & 550 & 100 & 260 & 100 & 290 & 100 & 550 & 100 \\
\hline \multicolumn{19}{|l|}{ Thickness* } \\
\hline Absence & 4 & 2 & 8 & 3 & 12 & 2 & 5 & 2 & 29 & 10 & 34 & 6 & 1 & 0 & 6 & 2 & 7 & 1 \\
\hline Thin & 69 & 26 & 106 & 37 & 175 & 32 & 61 & 24 & 48 & 17 & 109 & 20 & 128 & 49 & 115 & 40 & 243 & 44 \\
\hline Medium & 162 & 62 & 165 & 57 & 327 & 60 & 138 & 53 & 129 & 44 & 267 & 48 & 118 & 45 & 130 & 45 & 248 & 45 \\
\hline Large & 25 & 10 & 11 & 4 & 36 & 6 & 56 & 22 & 84 & 29 & 140 & 26 & 13 & 5 & 39 & 13 & 52 & 10 \\
\hline \multirow[t]{3}{*}{ Total } & 260 & 100 & 290 & 100 & 550 & 100 & 260 & 100 & 290 & 100 & 550 & 100 & 260 & 100 & 290 & 100 & 550 & 100 \\
\hline & \multicolumn{6}{|c|}{ Right eye } & \multicolumn{6}{|c|}{ Left eye } & \multicolumn{6}{|c|}{ Total } \\
\hline & \multicolumn{2}{|c|}{$\begin{array}{c}\text { Conc. } \\
(\%)\end{array}$} & \multicolumn{2}{|c|}{$\begin{array}{l}\text { Kappa } \\
(95 \% \mathrm{Cl})\end{array}$} & \multicolumn{2}{|c|}{$\begin{array}{l}\text { Kappa } \\
\text { pond. }\end{array}$} & \multicolumn{2}{|c|}{$\begin{array}{c}\text { Conc. } \\
(\%)\end{array}$} & \multicolumn{2}{|c|}{$\begin{array}{l}\text { Kappa } \\
(95 \% \mathrm{Cl})\end{array}$} & \multicolumn{2}{|c|}{$\begin{array}{l}\text { Kappa } \\
\text { pond. }\end{array}$} & \multicolumn{2}{|c|}{$\begin{array}{c}\text { Conc. } \\
(\%)\end{array}$} & \multicolumn{2}{|c|}{$\begin{array}{l}\text { Kappa } \\
(95 \% \mathrm{Cl})\end{array}$} & \multicolumn{2}{|c|}{$\begin{array}{l}\text { Kappa } \\
\text { pond. }\end{array}$} \\
\hline Tortuosity & & & & & & & & & & & & & & & & & & \\
\hline Obs 1 \& Obs 2 & 51 & & $\begin{array}{r}0 \\
0.16\end{array}$ & $\begin{array}{l}50 \\
0.33\end{array}$ & & & 46 & $\%$ & & $\begin{array}{l}27 \\
0.30\end{array}$ & & & 48 & $\%$ & $\begin{array}{r}0.2 \\
0.18\end{array}$ & $\begin{array}{l}40 \\
0.30\end{array}$ & 0.2 & 96 \\
\hline Obs 1 \& Obs 3 & 86 & $\%$ & $\begin{array}{r}0 \\
0.6\end{array}$ & $\begin{array}{l}49 \\
-0.82\end{array}$ & & & 84 & $\%$ & $\begin{aligned} 0 \\
0.6\end{aligned}$ & $\begin{array}{l}50 \\
-0.82\end{array}$ & & 76 & 85 & $\%$ & $\begin{array}{r}0.7 \\
0.70\end{array}$ & $\begin{array}{l}50 \\
0.80\end{array}$ & 0.7 & 774 \\
\hline Obs 2 \& Obs 3 & 56 & $\%$ & $\begin{array}{r}0 \\
0.2\end{array}$ & $\begin{array}{l}07 \\
-0.39\end{array}$ & & 46 & 46 & $\%$ & & $\begin{array}{l}25 \\
0.30\end{array}$ & & 76 & 51 & $\%$ & $\begin{array}{r}0.2 \\
0.20\end{array}$ & $\begin{array}{l}66 \\
-0.32\end{array}$ & 0.3 & 309 \\
\hline Width & & & & & & & & & & & & & & & & & & \\
\hline Obs $1 \&$ Obs 2 & 66 & $\%$ & $\begin{array}{r}0 \\
0.3\end{array}$ & $\begin{array}{l}33 \\
-0.53\end{array}$ & & 509 & 61 & $\%$ & & $\begin{array}{l}02 \\
-0.48\end{array}$ & & 00 & 64 & $\%$ & $\begin{array}{r}0 . \\
0.36\end{array}$ & $\begin{array}{l}19 \\
-0.48\end{array}$ & 0.5 & 510 \\
\hline Obs 1 \& Obs 3 & 90 & $\%$ & $\begin{array}{r}0 \\
0.7\end{array}$ & $\begin{array}{l}10 \\
0.88\end{array}$ & & 302 & 88 & $\%$ & & $\begin{array}{l}90 \\
-0.85\end{array}$ & & 14 & 89 & $\%$ & $\begin{array}{r}0.8 \\
0.76\end{array}$ & $\begin{array}{l}03 \\
0.85\end{array}$ & 0.8 & 312 \\
\hline Obs 2 \& Obs 3 & 66 & $\%$ & $\begin{array}{r}0 \\
0.3\end{array}$ & $\begin{array}{l}29 \\
-0.52\end{array}$ & 0.4 & 80 & 58 & $3 \%$ & & $\begin{array}{l}59 \\
-0.44\end{array}$ & & 70 & 62 & $\%$ & $\begin{array}{r}0 . \\
0.33\end{array}$ & $\begin{array}{l}95 \\
-0.45\end{array}$ & 0.4 & 81 \\
\hline
\end{tabular}


Regarding the continuous variables, the number and density of fibers and LCs were evaluated with Spearman's correlation. Once again, the number of fibers was more highly correlated between observers 1 and 3 with values 0.912 , 0.904 , and 0.913 for total, right, and left eye measures, respectively. For LCs, the correlation between viewers 1 and 3 reached 0.950 for the right and left eyes.

Considering intra-observer reliability, the 10 pictures for each patient were evaluated using the ICC correction. The results show low variability within each observer and for the variables studied. As expected, for the 10 evaluated photos (5 right and 5 left eyes) the pictures of the same subject and object were highly consistent. LCs had the highest intra-observer reliability with a total ICC $=0.96$ and 95\%CI 0.93-0.97. For the number of fibers, the results were similar when separately measuring the right $(\mathrm{ICC}=0.82$, $95 \%$ CI $0.53-0.91$ ) or left eye (ICC $=0.87,95 \%$ CI $0.71-0.93$ ), with greater variability for the right eye. For all observers, there was an ICC of 0.85 and, 95\%CI 0.65-0.92.

\section{Evaluation of CCM variables}

The correlation between the average number of fibers and subject age showed an inverse relationship between fiber number and density and age in women; that is, there was a reduction in the number and density of fibers with increasing age for women $(\mathrm{p}<0.05$, Figure 4$)$.

The relationships between demographic variables, thickness, and tortuosity with the number of LCs were verified by means of generalized linear models with Poisson model (used for quantifiable variables). In univariate analysis, there was a statistically significant relationship between age, sex, and thickness $(\mathrm{p}<0.001)$; therefore, all these variables were included in the multivariate model. These variables remained significant in the model $(\mathrm{p}<0.001)$. The results indicate that a 1-year increase in age corresponded with an average increase of 1.017 (95\%CI: 1.008-1.026) in the number of LCs, adjusting for sex and thickness. Similarly, the average number of LCs among women was $35 \%$ lower than for

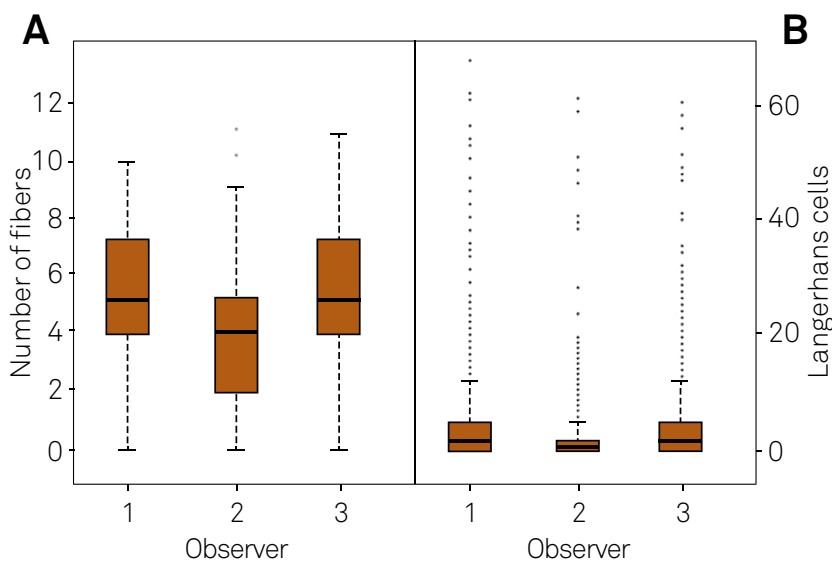

Figure 3. Data from all three observers. men, adjusted for the effect of age and thickness (odds ratio $[\mathrm{OR}]=0.645,95 \% \mathrm{CI}: 0.500-0.831$ ). Moreover, the average number of LCs among those with fibers with medium or large thickness was 1.13 times higher compared with those of thin fibers by controlling the effects of age and $\operatorname{sex}(\mathrm{OR}=2.13$, 95\%CI: 1.531-2.978). However, there were two outliers that should be considered in these results (Figure 5).

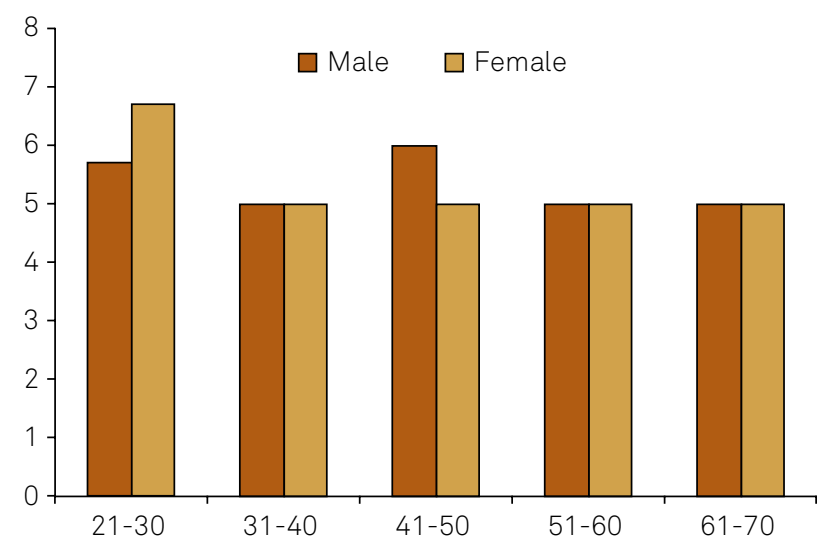

Figure 4. Average numbers of fibers by age group and sex.

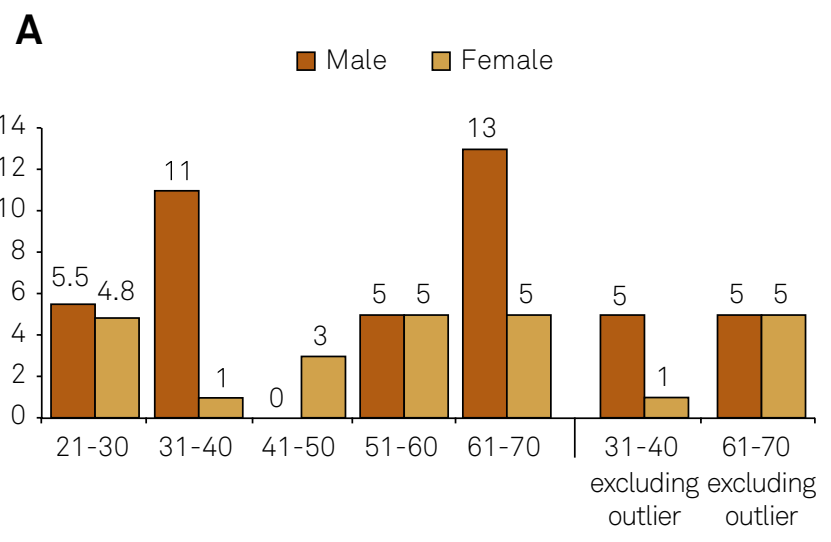

B

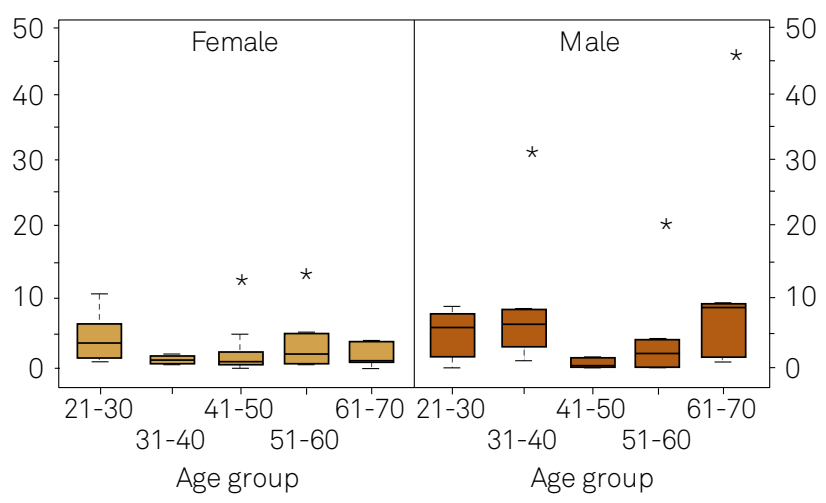

Figure 5. (A) Average numbers of Langerhans cells by age group and sex. Age categories 31-40 and 61-70 are represented twice to demonstrate the results excluding the outliers. Black and gray represent males and females, respectively. (B) Box plots showing numbers of Langerhans cells by age group and sex without the outliers. 
No statistically significant percentage difference was noted between demographic variables and fiber characteristics (tortuosity and thickness) (Figures 6 and 7).

\section{Discussion}

We analyzed 550 images from 55 healthy volunteers and found an inverse relationship between fiber number and age, with a decrease of 0.148 fibers for each additional year of age. This reduction was higher in females. We also observed that older individuals had more tortuous and thinner nerve fibers. This study is the first of its kind in a Brazilian population.

Other studies evaluating the density of fibers per field are shown in Table $3^{4,10,11,12}$. Only studies using the same methodology employed here were included. Our population had a greater mean number of fibers per field than the other studies.

Regarding the density of nerve fibers of the sub-basal epithelial plexus, there is variation depending on the type of confocal microscope used. Confocal microscopes can be laser scanning, scanning slit lamp, or tandem type. The differences between these microscopes are lighting intensity and type, resolution, and image contrast. Another issue exists regarding the definition of the method for measuring fiber density of the sub-basal epithelial plexus. Some authors consider the total length of nerve fibers visible in a defined area in $\mathrm{mm}^{213}$, while other authors ${ }^{14}$ consider the sum of the number of nerve fibers by field. In our study, we used a laser scanning microscope type and measured the density of nerve fibers as visible fibers per field microns per $\mathrm{mm}^{2}$. Analyses were made only through observation; no automated method was used. A clinical evaluation performed by a trained specialist is equivalent to results obtained with automated methods ${ }^{13,14,15}$. We cannot definitively say that there were no differences between these methodologies; however, there was no perceived compromise of the technique regarding our results.

Parissi's group ${ }^{12}$ evaluated 207 healthy eyes in subjects aged $88 \pm 15$ years and also found a negative correlation between nerve fiber density and age, reporting a decrease of $0.25 \%$ to $30 \%$ per year, regardless of sex, eye studied, or methodology used to delineate the nerve fibers. In accordance with earlier findings ${ }^{16,17}$, an inverse relationship was found between nerve fiber density and age. In our work, similar to the findings of Niederer ${ }^{4}$, this inverse correlation was more significant in women. For each 1-year increase in age, there is a reduction in the number of fibers (-0.148). Dehaghani's group $^{18}$ carried out a 3 -year longitudinal study and reported

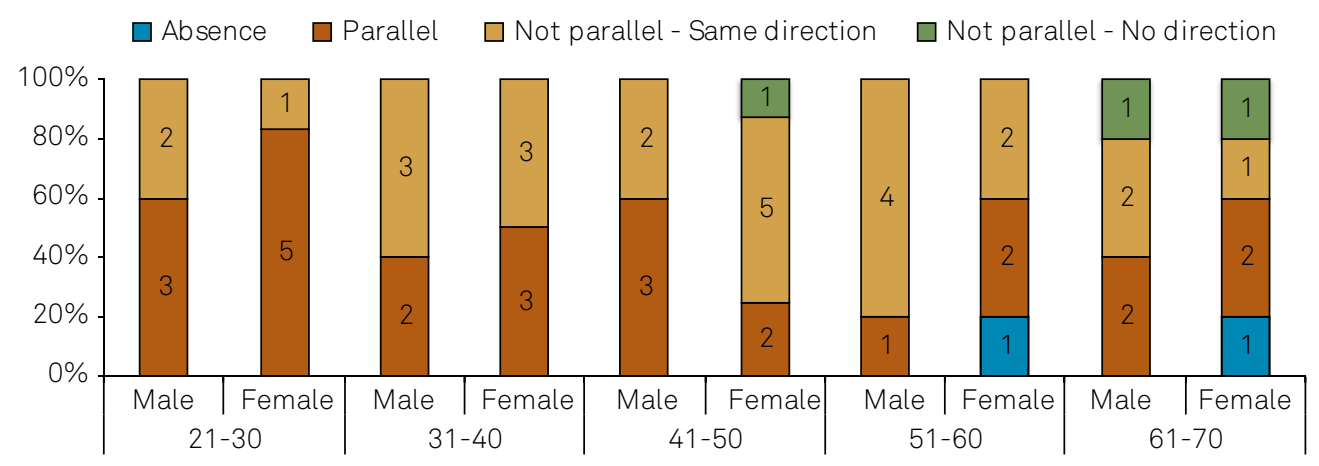

Figure 6. Tortuosity by age group, sex, and type. The numbers within the bars represent the number of patients with the specified shaded type.

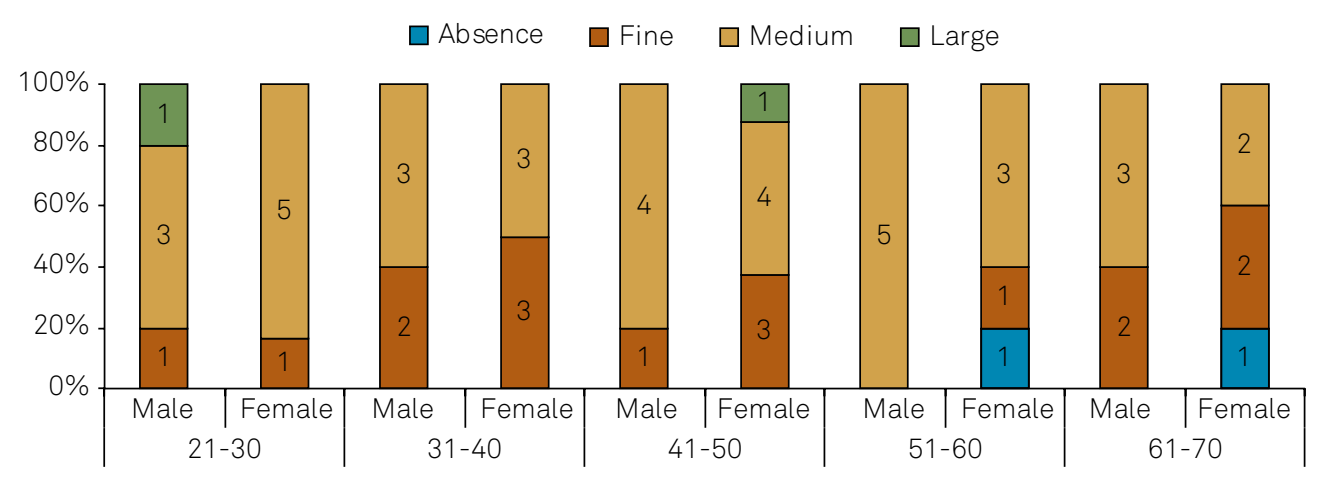


Table 3. Comparable studies.

\begin{tabular}{lccccc}
\hline Authors & Country & Age range & Sample size & Density & Standard deviation \\
\hline Patel et al., 200910 & New Zealand & $37 \pm 10$ & 31 eyes & 25.9 & 7 \\
Niederer et al., 2007'11 & New Zealand & $45 \pm 17$ & 30 eyes & 21.6 & 5.91 \\
Parissi et al., 2013'2 & Norway & $88 \pm 15$ & 207 eyes & 19 & 5.1 \\
Niederer et al., 20074 & New Zealand & $38 \pm 16$ & 170 eyes & 20.3 & 6.5 \\
Current Study & Brazil & $70 \pm 21$ & 110 eyes & 33.4 & 8.5 \\
\hline
\end{tabular}

that a reduction of $0.05 \mathrm{~mm} / \mathrm{mm}^{2}$ in the total length of the nerve fiber per field per year increased with age, but they did not observe differences between males and females.

As seen in Figure 2, the average number of fibers by age group and sex may be misleading. We observed a greater average number of fibers in the 20-30-year-old female group and then from the age of 30 onwards the average number reduces to 5 and remains consistent across until age 70 . This initial elevation gives rise to an annual decrease of 0.148 ; however, this may actually represent a shorter time-span, possibly decreasing from adolescence and plateauing after 30. This difference may disappear with a greater number of participants; therefore, the study should be repeated with a larger sample. It should be noted though that this trend of decreasing fibers in women over time has been reported by several other groups ${ }^{4,18}$; thus, the current literature lends itself to validating our findings rather than representing an artifact from a limited sample size.

Regarding nerve fiber tortuosity, our results as well as the others ${ }^{14}$ showed that most of the fibers were oriented in a direction perpendicular to the axis and slightly crooked. Individuals over the age of 30 years were more likely to have no parallel fibers, fewer perpendicular fibers, and more itytortuosity.
In our study of LCs, we found an age-dependent increase in the number. In individuals younger than 30 years, the prevalence of the cells was lower for females. The average number of cells for women was $35 \%$ lower than for men adjusted for the effect of age and sex. Our findings are consistent with other works evaluating $\mathrm{LCs}^{19}$.

Due to the two patients in our study who had an extremely high number of LCs for unknown reasons, the variation we saw was far greater than in other studies ${ }^{5}, 3.0 \pm 0.4$ per field compared to our $5.1 \pm 8.10$ cells $/ \mathrm{mm}^{2}$. This variation between the two studies is as expected for the technique. However, the reason for increased LCs in these two patients, who were reportedly healthy, is unclear. A study by Cruzat and colleagues ${ }^{5}$ demonstrated a correlation between plexus epithelial sub-basal zone, or the peripheral nervous system, and the cornea immune response. Assessing patients with infectious corneal keratitis, the authors reported a decrease in the number of nerve fibers and hence an increase in LC density in the acute phase of the disease.

The limitations of this study are clearly the small sample size, which is a restricted representation of the general Brazilian population. Nevertheless, we feel that offering a sample of each age group adds to the current literature and provides the first work in this area in Brazil.

\section{References}

1. Cruzat A, Pavan-Langston D, Hamrah P. In vivo confocal microscopy of corneal nerves: analysis and clinical correlation. Semin Ophthalmol. 2010; 25(5-6):171-7. doi:10.3109/08820538.2010.518133

2. Oliveira-Soto L, Efron N. Morphology of corneal nerves in soft contact lens wear. A comparative study using confocal microscopy. Ophthalmic Physiol Opt. 2003; 23(2):163-74. doi:10.1046/j.1475-1313.2003.00106.x

3. Schrems-Hoesl LM, Schrems WA, Cruzat A, Shahatit BM, Bayhan HA, Jurkunas $U$ V, et al. Cellular and subbasal nerve alterations in early stage Fuchs' endothelial corneal dystrophy: an in vivo confocal microscopy study. Eye (Lond). 2013;27(1):42-9. doi:10.1038/eye.2012.220

4. Niederer RL, Perumal D, Sherwin T, McGhee CNJ. Age-related differences in the normal human cornea: a laser scanning in vivo confocal microscopy study. Br J Ophthalmol. 2007;91(9):1165-9. doi:10.1136/bjo.2006.112656

5. Cruzat A, Witkin D, Baniasadi N, Zheng L, Ciolino JB, Jurkunas U $\checkmark$, et al. Inflammation and the nervous system: the connection in the cornea in patients with infectious keratitis. Invest Ophthalmol Vis Sci. 2011;52(8):5136-43. doi:10.1167/iovs.10-7048

6. Pupe CCB. Estudo das alterações morfológicas do plexo sub-basal epitelial da córnea através da microscopia confocal in vivo em pacientes com polineuropatia diabética sintomática comparados a controles [Thesis]. Rio de Janeiro: Universidade Federal Fluminense; 2014.

7. Rosenberg ME, Tervo TM, Immonen IJ, Müller LJ, Grönhagen-Riska C, Vesaluoma MH. Corneal structure and sensitivity in type 1 diabetes mellitus. Invest Ophthalmol Vis Sci. 2000;41(10):2915-21.

8. Tavakoli M, Marshall A, Thompson L, Kenny M, Waldek S, Efron $\mathrm{N}$, et al. Corneal confocal microscopy: a novel noninvasive means to diagnose neuropathy in patients with Fabry disease. Muscle Nerve. 2009;40(6):976-84. doi:10.1002/mus.21383

9. Ferrari G, Nalassamy N, Downs H, Dana R, Oaklander AL. Corneal innervation as a window to peripheral neuropathies. Exp Eye Res. 2013;113:148-50. doi:10.1016/j.exer.2013.05.016

10. Patel D V, Ku JYF, Johnson R, McGhee CNJ. Laser scanning in vivo confocal microscopy and quantitative aesthesiometry reveal decreased corneal innervation and sensation in keratoconus. Eye (Lond). 2009;23(3):586-92. doi:10.1038/eye.2008.52

11. Niederer RL, Perumal D, Sherwin T, McGhee CNJ. Corneal innervation and cellular changes after corneal transplantation: an in vivo confocal microscopy study. Invest Ophthalmol Vis Sci. 2007;48(2):621-6. doi:10.1167/iovs.06-0538 
12. Parissi M, Karanis G, Randjelovic S, Germundsson J, Poletti E, Ruggeri A, et al. Standardized baseline human corneal subbasal nerve density for clinical investigations with laserscanning in vivo confocal microscopy. Invest Ophthalmol Vis Sci. 2013;54(10):7091-102. doi:10.1167/iovs.13-12999

13. Patel DV, McGhee CNJ. In vivo confocal microscopy of human corneal nerves in health, in ocular and systemic disease, and following corneal surgery: a review. Br J Ophthalmol. 2009;93(7):853-60. doi:10.1136/bjo.2008.150615

14. Oliveira-Soto L, Efron N. Morphology of corneal nerves using confocal microscopy. Cornea. 2001;20(4):374-84. doi:10.1097/00003226-200105000-00008

15. Dabbah MA, Graham J, Petropoulos IN, Tavakoli M, Malik RA. Automatic analysis of diabetic peripheral neuropathy using multi-scale quantitative morphology of nerve fibres in corneal confocal microscopy imaging. Med Image Anal. 2011;15(5):738-47. doi:10.1016/j.media.2011.05.016
16. Grupcheva CN, Wong T, Riley AF, McGhee CNJ. Assessing the sub-basal nerve plexus of the living healthy human cornea by in vivo confocal microscopy. Clin Experiment Ophthalmol. 2002;30(3):187-90. doi:10.1046/j.1442-9071.2002.00507.x

17. Niederer RL, McGhee CNJ. Clinical in vivo confocal microscopy of the human cornea in health and disease. Prog Retin Eye Res. 2010;29(1):30-58. doi:10.1016/j.preteyeres.2009.11.001

18. Dehghani C, Pritchard N, Edwards K, Russell AW, Malik RA, Efron N. Fully automated, semiautomated, and manual morphometric analysis of corneal subbasal nerve plexus in individuals with and without diabetes. Cornea. 2014;33(7):696-702. doi:10.1097/IC0.0000000000000152

19. Zhivov A, Stave J, Vollmar B, Guthoff R. In vivo confocal microscopic evaluation of Langerhans cell density and distribution in the normal human corneal epithelium. Graefes Arch Clin Exp Ophthalmol. 2005;243(10):1056-61. doi:10.1007/s00417-004-1075-8

20. Landis JR, Koch GG. The measurement of observer agreement for categorical data. Biometrics. 1977;33(1);159-74. 